This is a post-print of an article published in:

Acta Acustica United with Acustica, 99 (3), 421-432: 2013.

DOI: http://dx.doi.org/10.3813/AAA.918623

Acta Acustica United with Acutica is available online via ingentaconnect at:

http://www.ingentaconnect.com/content/dav/aaua

\title{
Numerical investigation of the repeatability and reproducibility of laboratory sound insulation measurements
}

A. Dijckmans, G. Vermeir

KU Leuven, Department of Civil Engineering,

Kasteelpark Arenberg 40, B-3001 Leuven, Belgium

Arne.Dijckmans@bwk. kuleuven. be

May/June 2013 


\begin{abstract}
An extensive parametric study has been carried out with a wave based model to numerically investigate the fundamental repeatability and reproducibility of laboratory sound insulation measurements in the frequency range 50-200 Hz. Both the pressure method (according to ISO 10140-2) and the intensity method (according to ISO 15186-1 and ISO 15186-3) are investigated. The investigation includes the repeatability of the different measurement procedures, which depends on the influence of the microphone positions and the source position. The reproducibility of the sound insulation measurements in different test facilities is studied by looking at the influence of geometrical parameters like room and plate dimensions, aperture placement and aperture thickness. The results show that for small-sized test elements, the reproducibility of the intensity method is better. For heavy walls and lightweight double constructions, however, the predicted uncertainty is similar for the three measurement methods. The results of the reproducibility study are also used to investigate systematic differences between the pressure method and both intensity methods.
\end{abstract}




\section{Introduction}

An important issue in sound insulation measurements has been the repeatability and reproducibility $[1,2]$. The repeatability of measurements concerns within-laboratory variances. In building acoustics, this is related to the accuracy with which the average sound pressure levels in rooms and the average sound intensity levels at surfaces can be measured. This will depend on the measurement equipment, the number of microphone positions and their specific locations and the applied averaging time. The reproducibility concerns differences encountered between measurements done at different test facilities by different operators using different measurement equipment.

Concerning reproducibility, significant differences can be observed in the sound reduction index when measured in different laboratories, especially at low frequencies $[3,4,5,6]$. Here, the specific modal behavior of the different rooms and samples can significantly influence the measured sound insulation. Therefore the sound insulation depends on room dimensions, aperture dimensions, aperture placement and the panel boundary conditions. In order to improve the inter-laboratory reproducibility and the overall repeatability of the measurement results, guidelines were elaborated for the construction of test facilities and for the specific measuring procedures $[7,8]$. After the development of accurate sound intensity probes, the intensity method was elaborated as an alternative for the classical pressure method [9]. Experimental research into the reproducibility of sound insulation measurements has been continued with several round robin tests on lightweight and heavy walls $[10,11,12]$. Recently, the standards related to the pressure method were updated $[13,14,15]$. Pedersen et al. [1] proposed a new intensity method to improve the repeatability and reproducibility at low frequencies $(50-160 \mathrm{~Hz})$, which was incorporated in ISO 15186-3 [16].

Currently, a revision of ISO 717 is proposed [17]. This standard defines procedures to 
determine single-number quantities from sound insulation spectra. In the present standard, the weighted sound reduction index $R_{\mathrm{w}}$ and spectrum adaptation terms $C$ and $C_{\mathrm{tr}}$ are determined from the sound insulation spectrum between $100 \mathrm{~Hz}$ and $3150 \mathrm{~Hz}$. Spectrum adaptation terms for an enlarged frequency range (50-5000 Hz) may be calculated according to an informative annex. An important change in the revision is that low frequencies $(50-80 \mathrm{~Hz})$ are always included in the procedure to determine the suggested single-number quantities, $R_{\text {living }}$ and $R_{\text {traffic }}$. The equivalents of $R_{\text {living }}$ and $R_{\text {traffic }}$ are $R_{\mathrm{w}}+C_{50-5000}$ and $R_{\mathrm{w}}+C_{\mathrm{tr}, 50-5000}$, respectively. This has prompted discussions about the uncertainty of measurement procedures at the lower frequencies and the uncertainty of the new descriptors $[18,19]$. Based on measurement results, Scholl et al. [17] conclude that in general, an inclusion of the low frequencies leads to only minor changes of the uncertainties, but there are cases where the uncertainty increases noticeably. The uncertainty of the current and newly suggested single-number quantities has also been studied numerically [20]. For small windows and heavy, concrete walls, the uncertainty was not significantly changed. For double lightweight constructions, for which the single-number quantities are determined in the lowest frequency bands, however, the uncertainty was increased noticeably. As a result, larger safety margins will be needed in the acoustic design of lightweight constructions.

According to ISO 140-2 [21], the reproducibility value of the pressure method increases from $5.5 \mathrm{~dB}$ at $200 \mathrm{~Hz}$ to $9 \mathrm{~dB}$ at $100 \mathrm{~Hz}$, corresponding to a standard deviation of 2.0 and $3.2 \mathrm{~dB}$, respectively. Below $100 \mathrm{~Hz}$, the standard deviation is even larger. To minimize the increase in the standard deviation by the inclusions of low frequencies in the determination of the single-number quantities, the use of more reliable measurement procedures at low frequencies is necessary. It is also important to know whether the use of different measurement methods leads to systematic differences. Systematic differences 
between the pressure method and the classical intensity method according to ISO 15186-1 [9] have been discussed by several authors $[22,23,24,25]$. The intensity method typically yielded lower sound insulation values at the low frequencies than the pressure method, which can be partly explained by the Waterhouse correction [26]. The results in [25] indicated that the reproducibility of the sound intensity method was better for windows with high sound insulation because of problems with flanking transmission through the wall in which the window was fixed in the pressure method. ISO 15186-3 [16] states that the reproducibility of the adapted intensity method is, for all frequencies, estimated to be equal to or better than that found with the method of ISO 140-3 [8] at $100 \mathrm{~Hz}$. The estimated reproducibility standard deviation is $2.5 \mathrm{~dB}$ at $50-80 \mathrm{~Hz}$ and $2.0 \mathrm{~dB}$ at $100-160 \mathrm{~Hz}$. These values are based on 16 measurements on windows and plaster board walls carried out in four different European laboratories [1]. The measurements were also used to estimate the average differences between the two methods. In a Nordic round robin test with five laboratories [18], the reproducibility values for a double glazed window were decreased significantly by use of the adapted intensity method. The values were in good agreement with the estimated reproducibility values in the standard. Further round-robin tests or numerical investigations to confirm these values for the reproducibility and average differences, however, are missing to the authors knowledge. Therefore, the repeatability and reproducibility of the different laboratory measurement methods and the systematic differences between the methods are numerically investigated by means of an extensive parametric study in this paper.

The organization of this paper is as follows. The wave based transmission suite model used in the numerical analysis is discussed briefly in section 2. Details about the calculation of the sound reduction index according to the different standards and the parametric study are also given. In section 3 and section 4 , the model is used to investigate the 
repeatability and reproducibility of sound insulation measurements, respectively. Finally, systematic differences between the three laboratory measurement methods are discussed in section 5 .

\section{Numerical analysis}

\subsection{Wave based transmission suite model}

Previously, a wave based model has been developed to describe the direct sound transmission through multilayered walls between two reverberant rooms [27, 28]. With this model, the sound insulation of rectangular single and double walls placed between two rectangular rooms can be investigated. The model has been extended to allow for the investigation of the niche effect on the sound insulation [29].

In the model, flanking transmission is neglected. The side and back walls of the rooms are assumed rigid, while room damping is introduced by making the acoustic wave number complex. The plates are assumed homogeneous, isotropic and acoustically thin. The boundary conditions of the plates are simply supported, clamped or free.

A modal approach, based on the Rayleigh-Ritz method, is adopted to describe the structural responses. The transverse displacement of the plates is written as an expansion series. The plate displacement expansion functions are chosen so that they satisfy a priori the simply supported, clamped or free boundary conditions.

The wave based methodology is used to solve the acoustic part of the problem. The Wave Based Method (WBM) is a Trefftz-based deterministic prediction method for the steady-state dynamic analysis of coupled vibro-acoustic systems. A general description of the method can be found in [30]. In this method, the steady-state pressures are expressed in terms of a set of wave functions which are solutions of the homogeneous part 
of the Helmholtz equation. The contribution of the wave functions is determined by the boundary and continuity conditions, which are solved by means of a weighted residual formulation. After the wave function contribution factors are determined, post-processing of the results gives the properties of interest, like the sound pressure levels or sound intensity levels.

The wave based transmission suite model has been validated with a number of transmission loss measurements of single and double walls, carried out in the Laboratory of Acoustics at the KU Leuven [28]. Generally, the agreement between the wave based model and the measurements was good in a broad frequency range. In the low frequency range, the dynamic range determined by the modal behavior of the rooms and the walls was well predicted.

\subsection{Calculation of sound reduction indices}

\subsubsection{ISO 10140-2}

The sound reduction index $R$ is determined by following measurement formula [13]:

$$
R=L_{p \mathrm{e}}-L_{p \mathrm{r}}+10 \log \frac{S}{A_{\mathrm{r}}}
$$

$L_{p \mathrm{e}}$ and $L_{p \mathrm{r}}$ are the average sound pressure levels in the emitting and the receiving room, respectively. $S$ is the area of the free test opening in which the element is installed and $A_{\mathrm{r}}=\frac{0.16 V_{\mathrm{r}}}{T_{\mathrm{r}}}$ the equivalent sound absorption area in the receiving room, with $V_{\mathrm{r}}$ the volume and $T_{\mathrm{r}}$ the reverberation time.

The average sound pressure level in the room is calculated by analytical integration of the acoustic pressure over the inner room volumes. Alternatively, the average sound pressure level is determined from a number of microphone positions in the center of the room (see section 3.1). The microphone positions used in the calculations meet the criteria given in standard ISO 10140-4 [14]. 


\subsubsection{ISO $15186-1$}

The intensity sound reduction index $R_{I}$ is determined by following measurement formula $[9]:$

$$
R_{I}=L_{p e}-6-\left[L_{I \mathrm{n}}+10 \log \frac{S_{\mathrm{m}}}{S}\right]
$$

where $L_{p e}$ is the average sound pressure level in the emitting room, $L_{I \mathrm{n}}$ is the average normal sound intensity level over the measurement surface in the receiving room, $S$ is the area of the test element and $S_{\mathrm{m}}$ is the total area of the measurement surface.

The average normal sound intensity level is calculated by analytical integration of the normal intensity at the test panel. The normal intensity is determined from the pressures and normal velocities at the surface of the test panel. In this case, $S_{\mathrm{m}}=S$ and $L_{I n}+10 \log S$ gives the true sound power transmitted through the panel. Alternatively, the average intensity level is determined from a grid of intensity probe positions at a certain distance from the test panel (see section 3.1).

\subsubsection{ISO $15186-3$}

The intensity sound reduction index $R_{I \mathrm{~S}}$ is determined by following measurement formula [16]:

$$
R_{I \mathrm{~S}}=L_{p \mathrm{~S}}-9-\left[L_{I \mathrm{n}}+10 \log \frac{S_{\mathrm{m}}}{S}\right]
$$

where $L_{p \mathrm{~S}}$ is the average sound pressure level over the surface of the test element in the source room, $L_{I \mathrm{n}}$ is the average normal sound intensity level over the measurement surface in the receiving room, $S$ is the area of the test element and $S_{\mathrm{m}}$ is the total area of the measurement surface.

$L_{p \mathrm{~S}}$ is calculated by analytical integration of the sound pressure over the surface of the test element or from a limited number of microphone positions (see section 3.1). The 
wall in the receiving room opposite the test element has to be covered with an efficient sound-absorbing material, while the other surfaces of the receiving room may not be sound absorbing in the frequency range $50-160 \mathrm{~Hz}$. In this way, the receiving room is converted acoustically into a duct with propagating cross-modes above the lowest cut-on frequency.

In the simulations, the back wall of the receiving room is modeled as perfectly reflecting when determining $R$. In the calculation of $R_{I}$ and $R_{I S}$, the back wall of the receiving room is modeled as perfectly absorbing.

The sound reduction indices are calculated at 81 frequencies per one-third octave band. The average sound reduction index in each frequency band is calculated from the summated sound pressure levels $L_{p, 1 / 3}$ octave and summated intensity levels $L_{I \mathrm{n}, 1 / 3 \text { octave }}$ :

$$
\begin{aligned}
L_{p, 1 / 3 \text { octave }} & =10 \log \left(\sum_{i=1}^{81} 10^{L_{p, i} / 10}\right) \\
L_{I \mathrm{n}, 1 / 3 \text { octave }} & =10 \log \left(\sum_{i=1}^{81} 10^{L_{I \mathrm{n}, i} / 10}\right) .
\end{aligned}
$$

The calculation at 81 frequencies per one-third octave band assures the convergence of the average sound reduction index in the considered frequency bands (50-200 Hz) [28].

\subsection{Set-up for parametric study}

Five different test elements are considered in the parametric study:

- a $4 \mathrm{~mm}$ single glazing,

- a double glazing consisting of two glass panes with thickness $10 \mathrm{~mm}$ and $12 \mathrm{~mm}$, separated by an air cavity of $18 \mathrm{~mm}$,

- a double plasterboard wall with an air cavity of $100 \mathrm{~mm}$ and three $12.5 \mathrm{~mm}$ thick plasterboards at each side,

- a $10 \mathrm{~cm}$ concrete wall and 


\begin{tabular}{|l|cccc|}
\hline & $\rho\left[\mathrm{kg} / \mathrm{m}^{3}\right]$ & $E[\mathrm{MPa}]$ & $\eta[-]$ & $\nu[-]$ \\
\hline Glass & 2500 & 62000 & 0.025 & 0.24 \\
Concrete & 2400 & 33000 & 0.015 & 0.27 \\
Plasterboard & 1200 & 3540 & 0.030 & 0.30 \\
\hline
\end{tabular}

Table 1: Material data (density $\rho$, Young's modulus $E$, loss factor $\eta$, Poisson's ratio $\nu$ ) used in the simulations.

- a $15 \mathrm{~cm}$ concrete wall.

The material properties used in the parametric study are given in Table 1. The double glazing and the double plasterboard wall have a theoretical mass-spring-mass resonance frequency of $120 \mathrm{~Hz}$ and $40 \mathrm{~Hz}$, respectively. For the double plasterboard wall, cavity absorption is taken into account by making the acoustic wave number in the cavity complex, assuming an equivalent reverberation time of 0.5 seconds. Simply supported boundary conditions are assumed for all the test elements.

The influence of the number of microphone and intensity probe positions and the position of the sound source is investigated in a repeatability study in section 3. For the repeatability study, a simplified model of the reverberant rooms of the Laboratory of Acoustics at the KU Leuven has been used, as the model has been validated with measurements performed in these test rooms [28]. The reverberant rooms have a volume of $87 \mathrm{~m}^{3}$. The dimensions (width $\times$ height $\times$ length) used for the source and receiving room are $5.09 \mathrm{~m} \times 4.15 \mathrm{~m} \times 4.12 \mathrm{~m}$. A representative value of $1.5 \mathrm{~s}$ is taken for the reverberation time of the rooms in each frequency band. This meets the requirements of the standard [15]. Furthermore, the influence of the reverberation time on the predicted transmission loss is limited [28]. The full-sized test opening has dimensions (width $\times$ height) $3.25 \mathrm{~m} \times 2.95 \mathrm{~m}$, while the standardized small-sized test opening has dimensions $1.25 \mathrm{~m} \times 1.50 \mathrm{~m}$. 
The reproducibility is analysed in section 4 by simulating five different test facilities. Furthermore, the relative influence of the source and receiving room dimensions, the plate dimensions, the aperture position and the aperture dimensions is investigated. For the reproducibility study, the average sound pressure levels and sound intensity levels are determined analytically. In this way, within-laboratory variances, caused for instance by the sampling of the sound field, are excluded from the numerical analysis. The sound source is placed in the back corner of the source room. In this way every room mode is excited. The total reproducibility, as measured in round-robin tests, is determined by the within-laboratory variances and the between-laboratory variance [21]. Therefore, the effect of the within-laboratory variance on the total reproducibility of $R, R_{I}$ and $R_{I \mathrm{~S}}$ is also discussed.

\section{Repeatability}

\subsection{Microphone positions}

In the measurement of $R$ and $R_{I}$, the spatially averaged sound pressure level (SPL) in the source and/or the receiving room must be determined. Because the sound field is not ideally diffuse, especially below the Schroeder frequency of the rooms, the sound pressure must be measured at different locations and averaged. Simmons [31] compared different methods to measure the room average SPL, both numerically and experimentally. Alternatively, the average SPL can be measured with a continuously moving microphone. Averaging over a trajectory, which was investigated by Hopkins [32] and described in ISO 10140-4 [14], is not considered in the present study.

The variance of the average SPL caused by the sampling of the sound field was investigated by using 20 different sets of microphone positions in the emitting and the receiving 
room. In each case, the average SPL was determined with 5 or 10 microphone positions in the central part of the room. The minimum separation distances of the standard [14] were respected. With five microphone positions the distance between any combination of two microphones, was at least $1.4 \mathrm{~m}$. The standard deviation of $L_{p \mathrm{e}}$ and $L_{p \mathrm{r}}$ is shown in Fig. 1. The standard deviation of $L_{p \mathrm{r}}$ is smaller than $1 \mathrm{~dB}$ in most frequency bands when using 5 microphone positions. The standard deviation of $L_{p \mathrm{e}}$ is larger below $80 \mathrm{~Hz}$ and smaller at higher frequencies. Doubling the number of microphone positions, as proposed by the standard [14], improves the repeatability from $100 \mathrm{~Hz}$ on, but hardly reduces the uncertainty in the lowest frequency bands. It must be noted that it was not possible to locate 10 microphone positions using the minimum distances recommended for measurements at low frequencies [14]. It is difficult to find suitable microphone positions in the center of the room in order to reduce the strong influence of the room modes at low frequencies. The inclusion of one microphone position in the corner could improve the repeatability [31]. The predicted standard deviations are lower than the ones corresponding to the repeatability values given in ISO 140-2[21]. However, round robin tests [10] also indicated lower values, probably due to the automatic measurement procedures used nowadays. Furthermore, the theoretical model does not account for the uncertainty due to calibration errors or fluctuations in the sound field over time.

In the determination of $R_{I S}$, the average SPL over the surface of the test element has to be measured. According to the standard [16], $L_{p \mathrm{~S}}$ has to be measured by multiple fixed microphone positions evenly but asymmetrically distributed over the entire surface of the test specimen, including parts close to the edges and corners. The distance between the test specimen and microphone has to be less than $50 \mathrm{~mm}$. For test elements up to $3 \mathrm{~m}^{2}$, a minimum number of 6 microphone positions has to be used. For larger elements, a minimum number of 12 microphone positions is specified. 


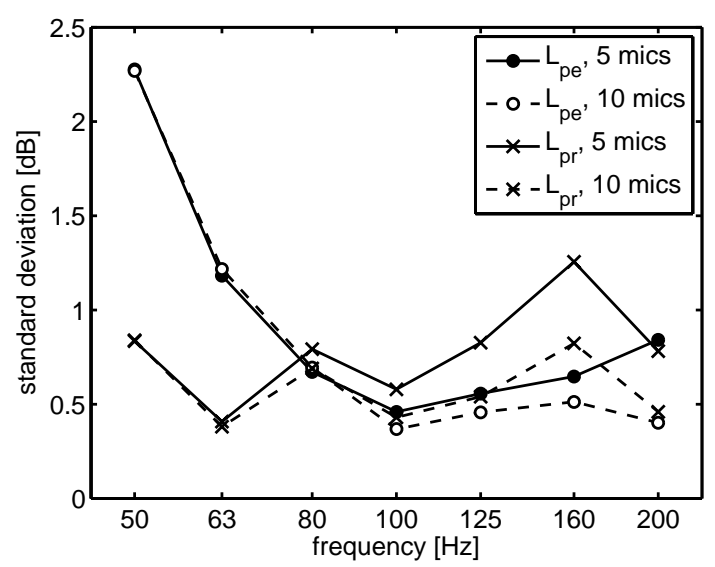

Figure 1: Standard deviation for 20 different sets of microphone positions of the average SPL in source and receiving room, determined with 5 or 10 microphone positions.

The uncertainty on the average SPL over the surface of a small test element (with dimensions $1.25 \mathrm{~m} \times 1.50 \mathrm{~m}$ ) and a large test element (with dimensions $3.25 \mathrm{~m} \times 2.95 \mathrm{~m}$ ) was investigated. In the simulations, niche effects were not taken into account. Figure 2 shows the standard deviation of $L_{p \mathrm{~S}}$ for 10 different sets of microphone positions, when $L_{p \mathrm{~S}}$ is determined with 6 microphone positions for the small test element and 12 microphone positions for the large test element. The results show that $L_{p \mathrm{~S}}$ can be determined with higher repeatability than $L_{p e}$, especially at low frequencies, as expected. As a result, the repeatability of $R_{I \mathrm{~S}}$ will be better than the repeatability of $R_{I}$.

In the intensity methods, the average sound intensity level on the receiving side, $L_{I \mathrm{n}}$, has to be measured. According to the standards $[9,16]$, it can be determined by scanning an intensity probe over a measurement surface or measuring the intensity at fixed positions. If the test specimen is mounted in a niche, the measurement surface is normally the flat surface of the niche opening. Measurement distances shorter than $10 \mathrm{~cm}$ should be avoided in view of a possibly high reactivity close to the wall.

The error caused by measuring the average intensity level over a measurement grid 


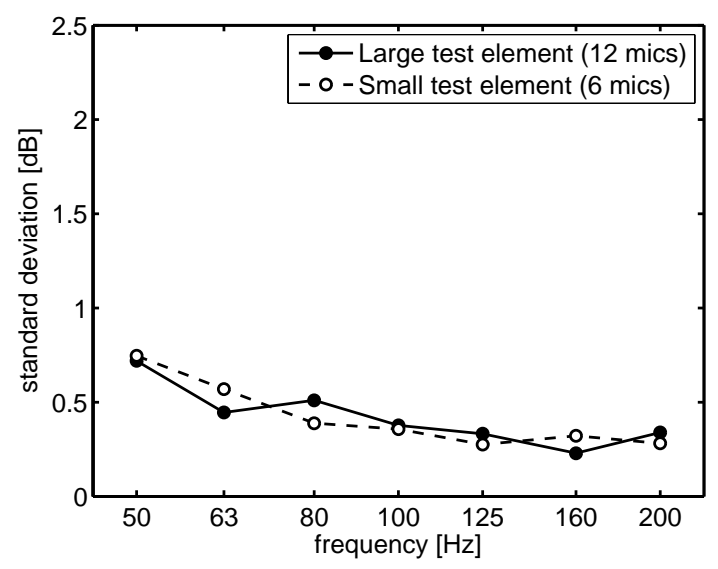

Figure 2: Standard deviation for 10 different sets of microphone positions of the average SPL over the surface of the test element in the source room, determined with 6 microphone positions for the small-sized test opening $(1.25 \mathrm{~m} \times 1.50 \mathrm{~m})$ and 12 microphone positions for the full-sized test opening $(3.25 \mathrm{~m} \times 2.95 \mathrm{~m})$.

was investigated numerically for the case of the $4 \mathrm{~mm}$ glazing $(1.25 \mathrm{~m} \times 1.50 \mathrm{~m})$ placed in a niche. The niche at the receiving side had the same dimensions as the glazing and a depth of $20 \mathrm{~cm}$. Figure 3 shows the difference $\Delta L_{I \mathrm{n}}=L_{I \mathrm{n}, \text { grid }}-L_{I \mathrm{n}, \text { ref }}$, where $L_{I \mathrm{n}, \mathrm{grid}}$ is the average sound intensity level determined with different measurement grids and $L_{I \mathrm{n} \text {,ref }}$ is the true average sound intensity level at the flat surface of the niche opening, determined analytically. For all measurement grids investigated, the true sound intensity is underestimated. When the probe is placed at the opening of the niche, the underestimation is limited to $0.5 \mathrm{~dB}$. By decreasing the spacing between the probe positions from $30 \mathrm{~cm}$ to $10 \mathrm{~cm}$, the measurement error is only reduced at 80 and $100 \mathrm{~Hz}$. The measurement error becomes larger when the intensity probe is not placed correctly at the opening of the niche and consequently, the measurement surface does not totally enclose the test specimen according to the guidelines [9]. The error increases to $1.5 \mathrm{~dB}$ and $3.5 \mathrm{~dB}$ when the probe is placed at $10 \mathrm{~cm}$ and $30 \mathrm{~cm}$ in front of the niche (i.e. further away from 


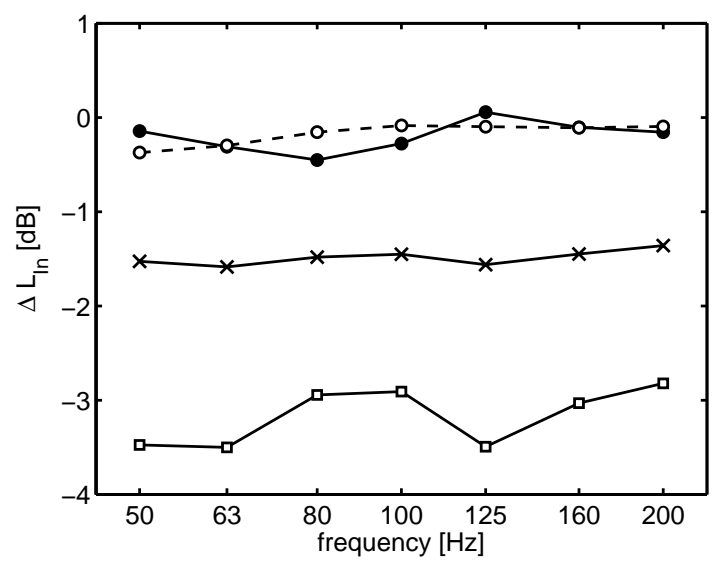

Figure 3: Difference between the true averaged sound intensity at the flat surface of the niche opening (reference) and the sound intensity averaged over different measurement grids. • Grid spacing of $30 \mathrm{~cm}$, at niche opening. ○ Grid spacing of $10 \mathrm{~cm}$, at niche opening, $\times$ Grid spacing of $30 \mathrm{~cm}, 10 \mathrm{~cm}$ in front of niche opening. $\square$ Grid spacing of 30 $\mathrm{cm}, 30 \mathrm{~cm}$ in front of niche opening.

the test element), respectively. In this case, the radiated sound power is underestimated because a part of the transmitted power is transported through the gap between the niche opening and the measurement surface at the sides.

\subsection{Source position}

The sound reduction index of structures depends on the angle of incidence of the incident sound waves. Measured and predicted sound reduction index values therefore depend on the distribution of incident energy over the angle of incidence. This is determined by the modal composition of the sound field, hence the source position and excitation mechanism are important [5]. In laboratory measurements, the objective is to make the sound field which is incident on the test object as diffuse as possible. Furthermore, the sound source must be placed at such a distance from the test specimen that the direct radiation upon 


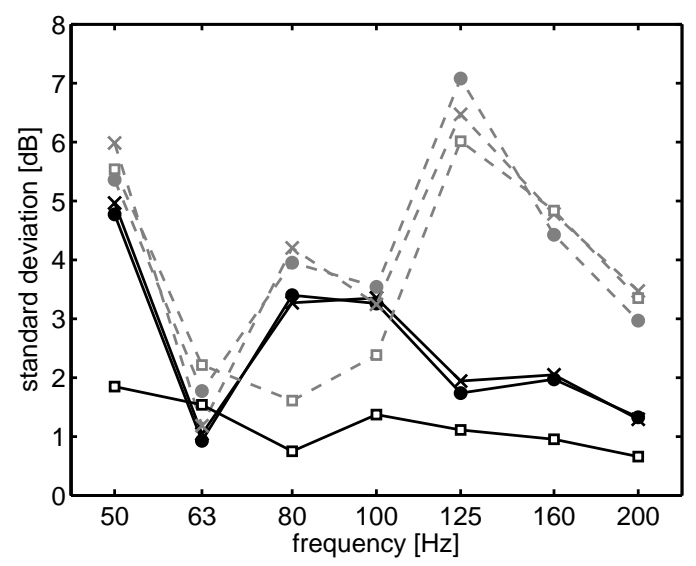

Figure 4: Standard deviation for 60 source positions of $R(\bullet), R_{I}(\times)$ and $R_{I S}(\square)$ of a 4 mm single glazing (solid lines) and a $15 \mathrm{~cm}$ concrete wall (dashed lines).

it is not dominant. Annex D of ISO 10140-5 [15] gives a procedure to find loudspeaker positions that reasonably represent the average of all possible loudspeaker positions in the source room.

To analyse the influence of the source position on $R, R_{I}$ and $R_{I \mathrm{~S}}$, an ideal point source was placed at 60 different positions in the center of the room, at a minimum distance of $0.7 \mathrm{~m}$ from the room boundaries according to the standard [15]. The standard deviation on the sound insulation of the single glazing and the $15 \mathrm{~cm}$ concrete wall are shown in Fig. 4. The average SPL's and transmitted sound intensity are calculated analytically. For the single glazing, the uncertainty caused by the sound source position is the same for $R$ and $R_{I}$, but significantly lower for $R_{I \mathrm{~S}}$ in most frequency bands. A similar decrease in uncertainty for $R_{I \mathrm{~S}}$ was found for the double glazing and the double plasterboard wall (not shown here for brevity). For the heavy concrete wall, the standard deviation is generally larger. Furthermore, the use of $R_{I S}$ does not improve the repeatability in most frequency bands. 


\section{Reproducibility}

\subsection{Study for five different test facilities}

In this section, the reproducibility of the different laboratory test methods for the sound reduction index are investigated. Five different test facilities are considered in the analysis. The room dimensions are based on the reverberation chambers of the Laboratory of Acoustics of the KU Leuven [28] and the four laboratories described in [1]. The reverberation chambers of the laboratories are modeled as rectangular rooms. The small-sized test elements are placed in a niche. The niches used in the models for the different laboratories all meet the requirements of ISO 10140-5 [15], but have slightly different dimensions. For the full-sized test openings (with different dimensions for the different laboratories), no niche is taken into account. The simulations are carried out for two directions of transmission, giving in total 10 values for $R, R_{I}$ and $R_{I \mathrm{~S}}$.

Figure 5 shows the standard deviations for the five different test elements investigated. The average SPL's and intensity levels are determined analytically to eliminate the withinlaboratory variance. The source was placed in the back corner of the source room. In general, the predicted standard deviations for the pressure method are larger the the ones corresponding to the reproducibility values given in the standard [21]. More recent round robin tests $[10,1]$ also indicated a larger uncertainty at low frequencies. Furthermore, the wave based model considers the worst case with no diffusers in the rooms. For most test elements, the standard deviation decreases with increasing frequency. For the $15 \mathrm{~cm}$ concrete wall, the standard deviation is still very large at $200 \mathrm{~Hz}$ because the wall has very few eigenmodes in the considered frequency range. The standard deviation for the small-sized test elements is smaller than that of the large walls. This is in agreement with results of round robin tests [1]. Furthermore, the uncertainty for the double glazing is 
larger than that for the single glazing from $80 \mathrm{~Hz}$ on. For the single glazing, the standard deviation of $R$ is twice as large as the standard deviation of $R_{I S}$. The standard deviation of $R_{I}$ lies in between these values. For the double glazing, the standard deviation of $R_{I \mathrm{~S}}$ is also the lowest, but the difference with the other methods is smaller. For the concrete walls, however, the reproducibility of the intensity methods is not better than that of the pressure method. The standard deviation of $R_{I}$ and $R_{I \mathrm{~S}}$ is even larger than that of $R$ in some frequency bands. This is in agreement with round robin test results for sand limestone walls, which indicated a similar reproducibility for the pressure and the intensity method at low frequencies [33]. For the double plasterboard wall, $R_{I}$ has the highest standard deviation. The standard deviation of $R_{I \mathrm{~S}}$ is approximately $1 \mathrm{~dB}$ smaller than that of $R$ between 50 and $80 \mathrm{~Hz}$, while no difference is seen at higher frequencies.

In measurements, the true average SPL's and intensity levels are not known. Estimations based on a limited number of sensor positions increase the uncertainty (see section 3.1). To analyse the influence on the reproducibility, the sound reduction indices were also determined from averages over a limited number of sensor positions. For $L_{p e}$ and $L_{p \mathrm{r}}, 5$ microphone positions were used. For $L_{p \mathrm{~S}}$, a total number of 6 and 12 microphone positions was used for the small-sized and large test elements, respectively. $L_{I n}$ was determined over a grid with a separating distance of $30 \mathrm{~cm}$. The results for the single glazing and the double plasterboard wall are shown in Fig. 6. It can be noticed that for the single glazing, the standard deviation of $R$ is increased due to within-laboratory differences, with an average increase between 0.5 and $1.5 \mathrm{~dB}$. For $R_{I}$ and $R_{I \mathrm{~S}}$, the standard deviation is not changed significantly. The repeatability study has indeed shown that the average SPL and intensity level at the surface of the small test elements can be determined more accurately than the average SPL in the rooms. For the double plasterboard wall, the increase of the standard deviation of $R$ is smaller (0 to $0.5 \mathrm{~dB})$, whereas the standard 
deviation of $R_{I}$ and $R_{I \mathrm{~S}}$ is increased by $0.5-1 \mathrm{~dB}$ and $0.5 \mathrm{~dB}$, respectively. For the large test elements that do not entirely cover the partition wall and where no niche is present, the measurement surface used in the predictions does not totally enclose the test element. Therefore, the average intensity levels are less accurate in this case.

In the next subsections, the relative importance of different parameters like the room dimensions, the plate dimensions, the aperture position and the aperture dimensions (niche effects) is investigated. Each parameter is varied exclusively without affecting other parameters. The niche effects of the test opening were not taken into account when investigating the influence of the room dimensions, the plate dimensions and the aperture position, The average SPL's and intensity levels were determined analytically to eliminate the within-laboratory variance. The source was placed in the back corner of the source room. 


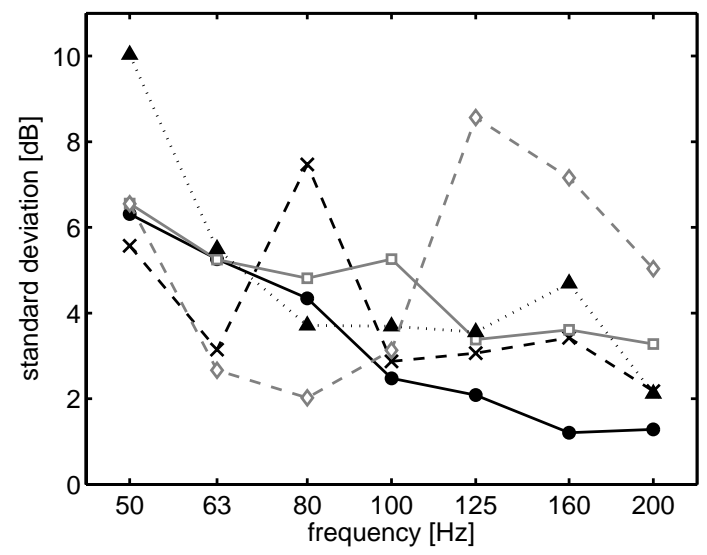

(a) $R$ according to ISO $10140-2$

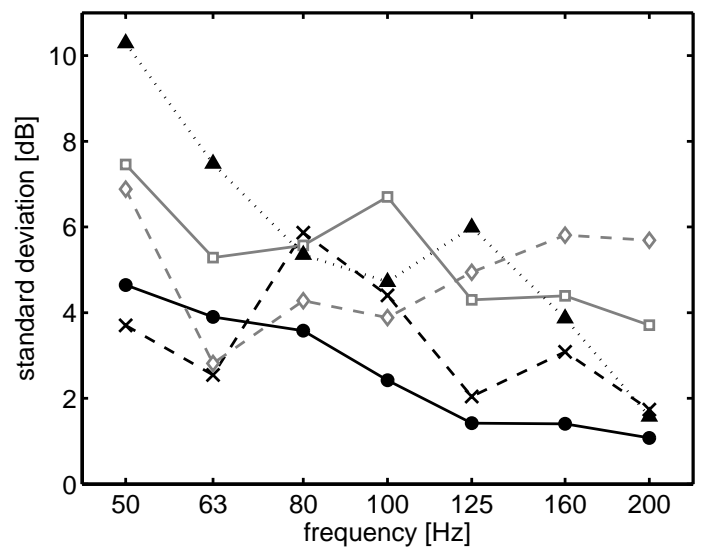

(b) $R_{I}$ according to ISO $15186-1$



(c) $R_{I \mathrm{~S}}$ according to ISO $15186-3$

Figure 5: Standard deviation for 5 different test facilities, for two directions of transmission, of a $4 \mathrm{~mm}$ single glazing $(\bullet)$, a double glazing $(\times)$, a double plasterboard wall $(\square)$, a $10 \mathrm{~cm}$ concrete wall $(\boldsymbol{\Lambda})$ and a $15 \mathrm{~cm}$ concrete wall $(\diamond)$. 


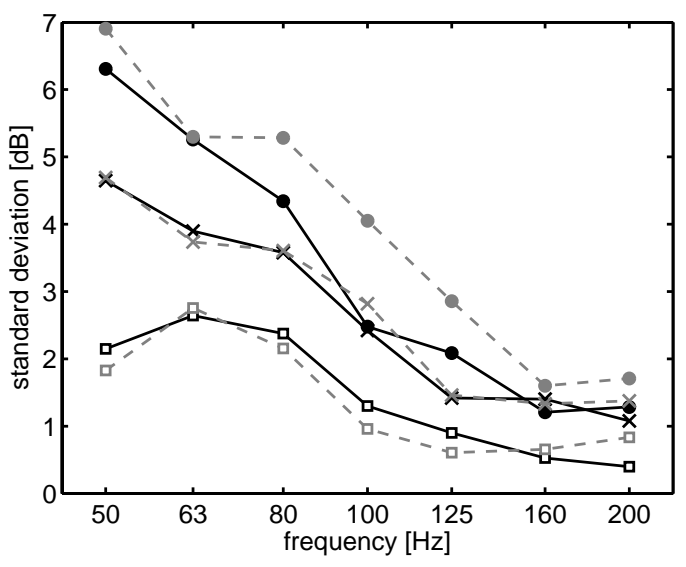

(a) $4 \mathrm{~mm}$ glazing

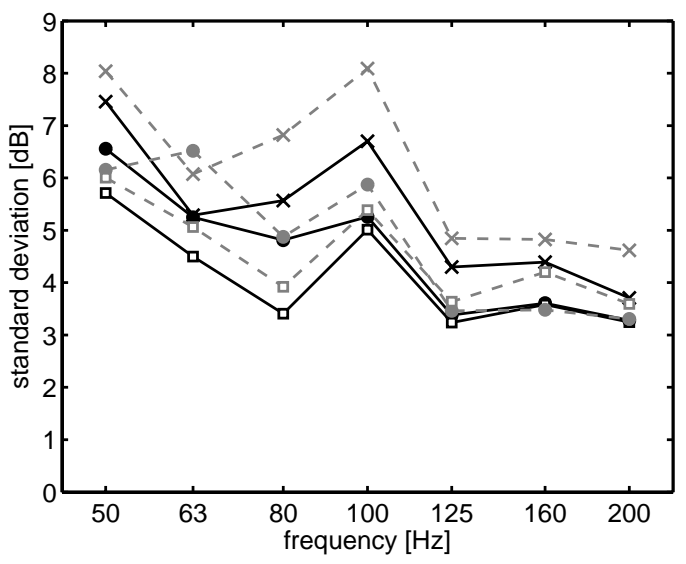

(b) Double plasterboard wall

Figure 6: Standard deviation for 5 different test facilities, for two directions of transmission of $R(\bullet), R_{I}(\times)$ and $R_{I \mathrm{~S}}(\square)$. Analytical determination of average SPL and intensity level (solid lines) and SPL and intensity level averaged over a limited number of sensor positions (dashed lines). 


\subsection{Influence of room dimensions}

The room dimensions determine the eigenfrequencies of the sending and the receiving room and in this way the modal coupling between the modes in both rooms. Therefore, the sound transmission through a structure will depend on the dimensions of the source and the receiving room.

The effect of the source room dimensions and receiving room dimensions were analysed separately. The pressure and intensity sound reduction indices for the different test elements were calculated for 50 different source rooms and 50 different receiving rooms. While varying the dimensions of one room, the dimensions of the other room (width $4.0 \mathrm{~m}$, height $3.4 \mathrm{~m}$, length $5.25 \mathrm{~m})$ and the plate dimensions $(1.25 \mathrm{~m} \times 1.5 \mathrm{~m}$ for the small elements and $3.25 \mathrm{~m} \times 2.95 \mathrm{~m}$ for the large elements) were fixed. All rooms had a volume of at least $50 \mathrm{~m}^{3}$ as specified in the standard [15]. For all the rooms, a frequency independent value of $1.5 \mathrm{~s}$ has been used for the reverberation time so that the requirements of the standard [15] are met. Furthermore, the influence of the reverberation time on the predicted transmission loss is negligible compared to the influence of the room dimensions [28].

Figure 7 shows the influence of the source room dimensions on the sound reduction index of the single glazing, the $15 \mathrm{~cm}$ concrete wall and the double plasterboard wall. The standard deviation of $R$ of the single glazing decreases from $2.5-3 \mathrm{~dB}$ below $100 \mathrm{~Hz}$ to $1 \mathrm{~dB}$ at $200 \mathrm{~Hz}$. The standard deviation of $R_{I}$ and $R_{I \mathrm{~S}}$ is respectively $0.5 \mathrm{~dB}$ and $1 \mathrm{~dB}$ lower in most frequency bands. The standard deviation of $R$ of the double plasterboard wall has a constant value around $3 \mathrm{~dB}$. The standard deviation is decreased by $1-1.5 \mathrm{~dB}$ for both intensity methods. For the double glazing, the simulations also showed a smaller standard deviation for the intensity methods (not shown here for brevity). For the $15 \mathrm{~cm}$ concrete wall, the uncertainty is larger with standard deviations of 5 to $6 \mathrm{~dB}$ below 80 


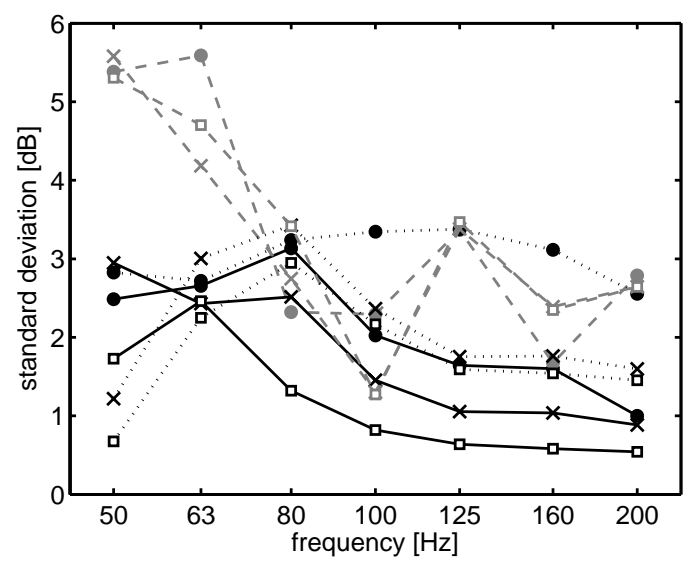

Figure 7: Standard deviation for 50 source rooms (volume $>50 \mathrm{~m}^{3}$ ) of $R(\bullet), R_{I}(\times)$ and $R_{I \mathrm{~S}}(\square)$ of a $4 \mathrm{~mm}$ single glazing (solid lines), a double plasterboard wall (dotted lines) and a $15 \mathrm{~cm}$ concrete wall (dashed lines).

$\mathrm{Hz}$ and 2 to $3 \mathrm{~dB}$ at higher frequencies. Furthermore, the use of the intensity method does not assure a decrease in the uncertainty. The same trend was observed for the $10 \mathrm{~cm}$ thick concrete wall. For heavy walls with a low modal density, the transmission loss shows a strong modal behavior in the lowest frequency bands. A change in room dimensions will affect the geometrical coupling between the plate and room modes, resulting in a significant change in the transmission loss of heavy walls. As the uncertainty is caused by the modal behavior, a change of measurement procedure will hardly solve the problem of reproducibility in this case [5].

Figure 8 shows the influence of the receiving room dimensions on the sound reduction index of the single glazing, the $15 \mathrm{~cm}$ concrete wall and the double plasterboard wall. The results for the other test elements are not shown for brevity. For the pressure method, the uncertainty related to the receiving room dimensions is very similar to the uncertainty caused by the source room dimensions for all the test elements investigated. This can be expected because the SPL difference is influenced by the modal behavior of both the source 


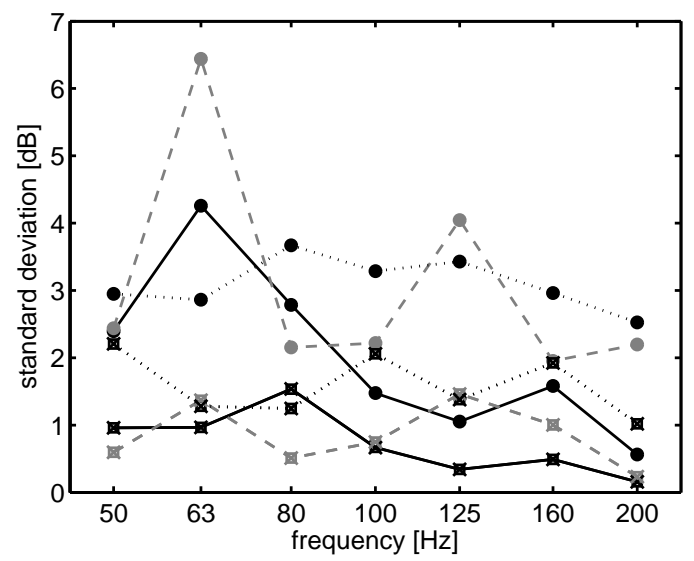

Figure 8: Standard deviation for 50 receiving rooms (volume $>50 \mathrm{~m}^{3}$ ) of $R(\bullet), R_{I}(\times)$ and $R_{I \mathrm{~S}}(\square)$ of a $4 \mathrm{~mm}$ single glazing (solid lines), a double plasterboard wall (dotted lines) and a $15 \mathrm{~cm}$ concrete wall (dashed lines).

and the receiving room. The modal behavior of the receiving room is much less important in the intensity method due to the absorbing back wall and the direct measurement of the transmitted sound power. The standard deviations for $R_{I}$ and $R_{I s}$ are the same. For all the test elements investigated, the standard deviations for the intensity methods are smaller than $2 \mathrm{~dB}$. Measurement results in [1] indicated that the smaller standard deviation for the intensity methods is mainly caused by the absorbing back wall in the receiving room.

\subsection{Influence of plate dimensions}

According to ISO 10140-5 [15], laboratory measurements of walls must be carried out in a full-size test opening with an area of approximately $10 \mathrm{~m}^{2}$, with the length of the shorter edge being not less than $2.3 \mathrm{~m}$. Here, the influence of the plate dimensions of the large test elements is investigated. Glazing and windows are placed in a standardized small-sized test opening with dimensions $1.25 \mathrm{~m} \times 1.50 \mathrm{~m}$, so the reproducibility for these elements 


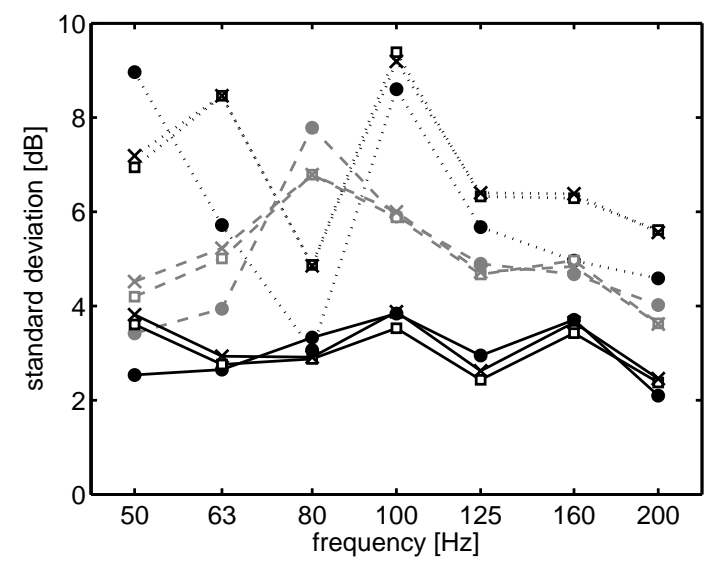

Figure 9: Standard deviation for 21 plate areas (area of $8.5-13 \mathrm{~m}^{2}$ ) of $R(\bullet), R_{I}(\times)$ and $R_{I \mathrm{~S}}(\square)$ of a double plasterboard wall (solid lines), a $10 \mathrm{~cm}$ concrete wall (dashed lines) and a $15 \mathrm{~cm}$ concrete wall (dotted lines).

is not influenced by the plate dimensions.

Simulations were carried out for 21 plates with varying dimensions. The plates had an area between 8.5 and $13 \mathrm{~m}^{2}$. In each case, the smallest edge was minimal $2.4 \mathrm{~m}$. The dimensions of the source room (width $5.0 \mathrm{~m}$, height $3.9 \mathrm{~m}$, length $5.25 \mathrm{~m}$ ) and the receiving room (width $5.0 \mathrm{~m}$, height $3.9 \mathrm{~m}$, length $3.75 \mathrm{~m}$ ) were kept constant. In each case, the test element was placed in the middle of the common wall.

Figure 9 shows the influence of the plate dimensions on the sound reduction index of the double plasterboard wall, the $10 \mathrm{~cm}$ concrete wall and the $15 \mathrm{~cm}$ concrete wall. The plate dimensions have a large influence on the sound transmission, especially for the heavy concrete walls which have very few eigenmodes in the frequency range of interest. Therefore, the standard deviations are very large for $R, R_{I}$ and $R_{I \mathrm{~S}}$ for the concrete walls. The $15 \mathrm{~cm}$ concrete wall has the lowest modal density and thus the highest standard deviations. This is in agreement with the results of a round robin test for two sand limestone walls (thickness $102 \mathrm{~mm}$ and $210 \mathrm{~mm}$ ), where the standard deviations of the 
heavier wall were the highest [33]. Comparison with Fig. 7 and Fig. 8 shows that the standard deviations for the $15 \mathrm{~cm}$ concrete wall are larger in this case. Also for the double plasterboard wall, the uncertainty related to the plate dimensions is more important than the uncertainty related to the dimensions of source and receiving room. The results also indicate that the influence of the plate dimensions cannot be decreased by use of the intensity method. For the $15 \mathrm{~cm}$ concrete wall, the standard deviation is even increased. At low frequencies, where the bending wave length of the walls is of the same order of magnitude as the wall dimensions, the sound transmission is strongly affected by the plate dimensions. Even if it were possible to measure the incident and transmitted sound power correctly, the problem of reproducibility remains [5, 28].

\subsection{Influence of aperture position}

Not only elements that change the modal composition of the sound field in the source or the receiving room - like the room dimensions or the source position - but also factors that change the modal coupling between the two rooms, influence the sound transmission. Geometrical coupling is determined by the geometry of the interface, the dimensions of the aperture and the position of the aperture. In this subsection, the influence of the position of the aperture for small test elements is investigated. In the next subsection, the effect of the dimensions of the aperture is studied.

Simulations were performed with 15 different positions of the aperture for the single and double glazing. The minimum distance between the small-sized test opening and any wall, floor or ceiling of either room is $500 \mathrm{~mm}$ as specified in the standard [15]. Niche effects of the test opening were not taken into account. The dimensions of the source room (width $4.25 \mathrm{~m}$, height $3.1 \mathrm{~m}$, length $5.6 \mathrm{~m}$ ) and the receiving room (width $4.25 \mathrm{~m}$, height $3.1 \mathrm{~m}$, length $4.6 \mathrm{~m}$ ) were kept constant. 


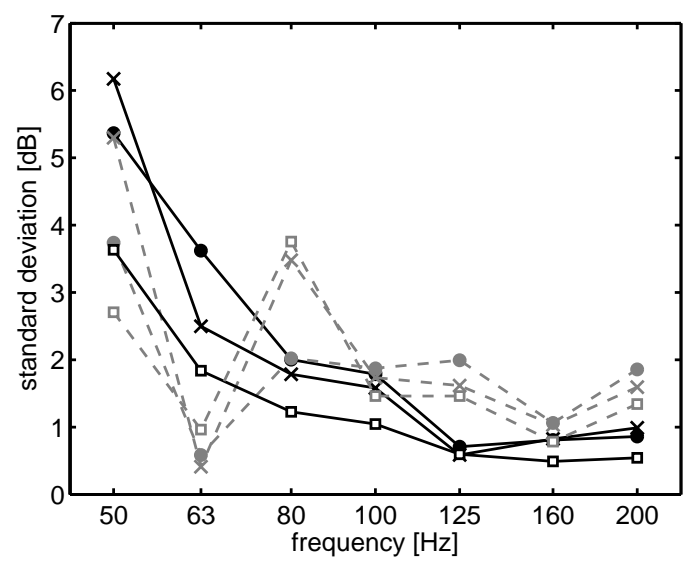

Figure 10: Standard deviation for 15 different aperture positions of $R(\bullet), R_{I}(\times)$ and $R_{I \mathrm{~S}}(\square)$ of a $4 \mathrm{~mm}$ single glazing (solid lines) and a double glazing (dashed lines).

Figure 10 shows the influence of the aperture position on the sound reduction index of the single and the double glazing. For the single glazing, the standard deviation decreases monotonically from 4-6 dB at $50 \mathrm{~Hz}$ to $0.5-1 \mathrm{~dB}$ at $200 \mathrm{~Hz}$. Furthermore, the uncertainty of $R_{I \mathrm{~S}}$ is systematically lower than that of $R$ and $R_{I}$. The standard deviation of the sound insulation of the double glazing is larger than that of the single glazing above the mass-spring-mass resonance frequency of about $120 \mathrm{~Hz}$.

\subsection{Influence of aperture dimensions (niche effect)}

The position of the plate in the aperture can have a significant influence on the sound reduction index, known as the niche effect [29]. The niche dept and the element placement can change the sound reduction index of single panels with more than $5 \mathrm{~dB}$ and the sound reduction index of double panels with more than $8 \mathrm{~dB}$, especially below coincidence. For the measurement of windows and glazing, a detailed description of the test aperture and test element placement in the niche is prescribed to eliminate differences caused by the niche effect as much as possible $[13,15]$. The test opening for windows and glazing should 




Figure 11: Standard deviation for 20 different aperture dimensions of $R(\bullet), R_{I}(\times)$ and $R_{I \mathrm{~S}}(\square)$ of a $4 \mathrm{~mm}$ single glazing (solid lines) and a double glazing (dashed lines).

have a maximum depth of $500 \mathrm{~mm}$, with staggered niches with a reflective finish. The larger niche should be $60 \mathrm{~mm}$ to $65 \mathrm{~mm}$ wider at the sides and the top. The niche depths on each side of the test element must be different and should be in the ratio 2:1.

Here, simulations were carried out for 10 different aperture dimensions. The test openings had a total depth of $300 \mathrm{~mm}, 400 \mathrm{~mm}$ and $500 \mathrm{~mm}$. The test elements were placed in the opening at a position 1:3, 1:2 and 2:3. A staggered niche with a step of $60 \mathrm{~mm}$ or $65 \mathrm{~mm}$ was simulated. Simulations were performed with both the larger and the smaller niche placed at the source room side, giving a total of 20 simulation results. The aperture position, the source room dimensions (width $4.1 \mathrm{~m}$, height $3.0 \mathrm{~m}$, length $5.7 \mathrm{~m}$ ) and the receiving room dimensions (width $4.1 \mathrm{~m}$, height $3.0 \mathrm{~m}$, length $4.5 \mathrm{~m}$ ) were kept constant.

The standard deviation of the sound insulation of the single and the double glazing is shown in Fig. 11. Overall, the standard deviation is smaller than $2 \mathrm{~dB}$ because the variation in the niche dimensions allowed by the standard is limited. At 80 and $100 \mathrm{~Hz}$, however, the standard deviation for $R$ and $R_{I}$ is significantly larger. This large uncertainty 
is caused by a systematic difference of 5 to $10 \mathrm{~dB}$ between the simulations with the larger niche at the sending and the receiving side, respectively. For $R_{I \mathrm{~S}}$, the orientation of the staggered niche has much less influence. This may be explained by the fact that the niche will affect the SPL distribution over the test element, which is incorporated in the measurement of $R_{I S}$, because the SPL at the surface of the test element is measured.

\subsection{Discussion of results}

The results of the reproducibility study can be used to better understand the standard deviations predicted for the five test facilities in section 4.1.

For the single and the double glazing, the uncertainty is similar for all the parameters investigated (room dimensions, aperture position and aperture dimensions). The standard deviation for the source room dimensions is somewhat higher, especially for the double glazing. Because the uncertainty of $R_{I \mathrm{~S}}$ is smaller than that of $R$ for all these parameters, the reproducibility of $R_{I S}$ will be better for small-sized test elements. This is in line with measurement results on small-sized test elements $[1,18]$.

The more complex behavior of the double glazing typically yields a higher variability in sound reduction index results compared to the single glazing results. Measurements on a single and double steel panel showed a similar trend [25]. Especially above the mass-spring-mass resonance frequency, the sound reduction index is more sensitive to the parameters investigated. Because the sound transmission through double glazing is strongly dependent on the angle of incidence in this frequency range, the influence of the source room dimensions, the aperture position and the aperture dimensions - which determine the directional distribution of incident energy - is more pronounced [27, 28].

For the heavy concrete walls, the uncertainty caused by the plate dimensions is the most important. The influence of the source room dimensions and the plate dimensions 
on $R, R_{I}$ and $R_{I \mathrm{~S}}$ is similar. Only the influence of the receiving room dimensions is decreased for the intensity method. Therefore, the global reproducibility of $R_{I \mathrm{~S}}$ is not better than that of $R$ or $R_{I}$ for this type of walls with a low modal density.

For the double plasterboard wall, the influence of the source room dimensions, receiving room dimensions and plate dimensions on $R$ is similar, with standard deviations between $2.5 \mathrm{~dB}$ and $3.5 \mathrm{~dB}$ in all frequency bands. The standard deviation of $R_{I \mathrm{~S}}$ for the room dimensions is reduced to 1.5 to $2 \mathrm{~dB}$, but stays the same for the plate dimensions. As a result, the global reproducibility of $R_{I \mathrm{~S}}$ is only slightly better than that of $R$. Calculations with a modal model showed a similar trend [1]. Results from round robin tests on two double walls [1], however, showed a larger improvement when using the adapted intensity method of ISO 15186-3.

\section{$5 \quad$ Systematic differences}

The calculations performed in the reproducibility study were used to analyse the systematic difference between the sound reduction index $R$, the intensity sound reduction index $R_{I}$ and the intensity sound reduction index $R_{I \mathrm{~S}}$. Systematic differences between the pressure method and the intensity method are expected [1] because of (i) the difference in the measurement of the transmitted power, (ii) the increase of absorption in the receiving room in the intensity method and (iii) the suppression of flanking transmission in the intensity method. The wave based model allows to investigate the first two causes theoretically, while the effect of flanking transmission is disregarded in the model. For $R_{I \mathrm{~S}}$, further systematic differences are expected because the incident sound power is determined from the SPL at the surface instead of the room average SPL. 


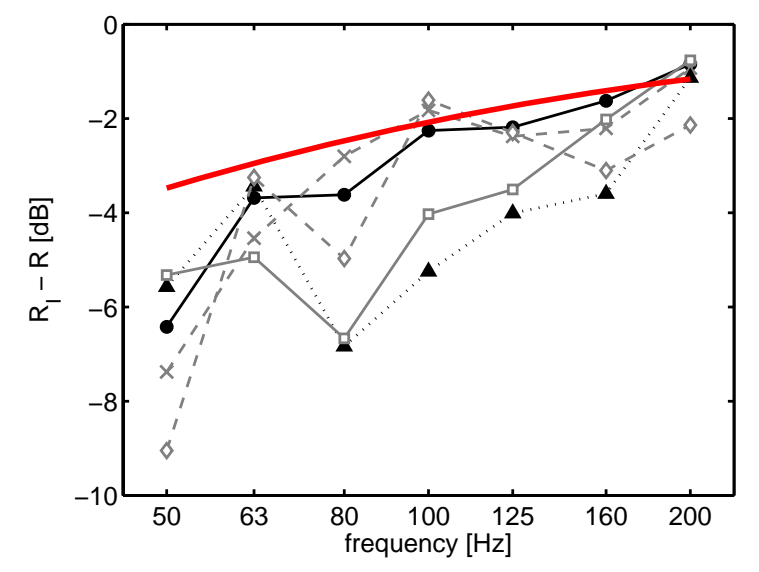

(a) $R_{I}-R$. The thick line is the Waterhouse correc-

tion factor according to Table B.1 of ISO 15186-1.

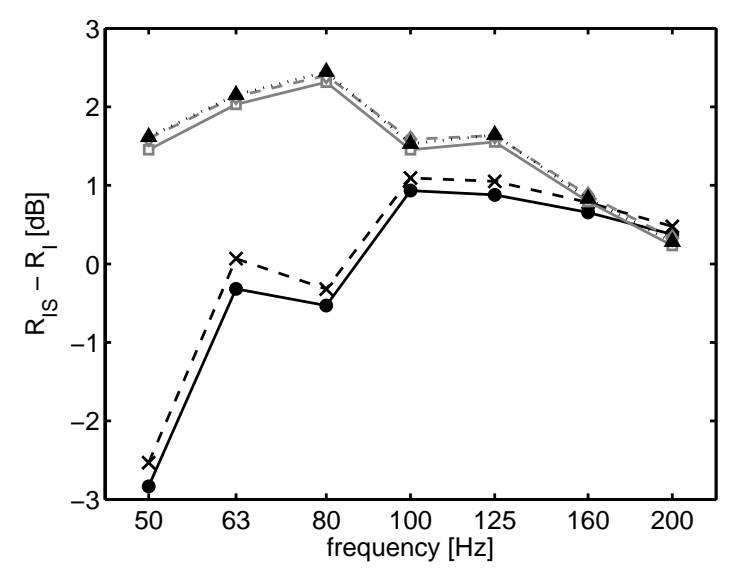

(b) $R_{I \mathrm{~S}}-R_{I}$



(c) $R_{I \mathrm{~S}}-R$. The thick line is the estimated average difference according to ISO 15186-3.

Figure 12: Systematic differences between $R, R_{I}$ and $R_{I \mathrm{~S}}$ (average of all simulations in the reproducibility study) for a $4 \mathrm{~mm} \operatorname{singhe} 1$ glazing $(\bullet)$, a double glazing $(\times)$, a double plasterboard wall $(\square)$, a $10 \mathrm{~cm}$ concrete wall $(\mathbf{\Delta})$ and a $15 \mathrm{~cm}$ concrete wall $(\diamond)$. 
Figure 12 shows the average difference between the three measurement methods for all the simulations carried out in the reproducibility study of section 4. Figure 12(a) gives the difference between $R$ and $R_{I} . R_{I}$ is lower than $R$ at all frequencies. The differences decreases from 5-9 dB at $50 \mathrm{~Hz}$ to $1-2 \mathrm{~dB}$ at $200 \mathrm{~Hz}$ for the different test elements. This systematic difference is partly related to the Waterhouse correction in the receiving room [26]. In the pressure method, the transmitted sound power is underestimated because it is based on the average SPL in the inner volume of the room. Furthermore, the absorptive back wall in the receiving room changes the modal behavior of the receiving room and thus the sound transmission.

The difference between $R_{I}$ and $R_{I \mathrm{~S}}$ lies between $+3 \mathrm{~dB}$ and $-3 \mathrm{~dB}$ below $100 \mathrm{~Hz}$ and decreases to $0.5 \mathrm{~dB}$ at $200 \mathrm{~Hz}$ [see Fig. 12(b)]. The difference is caused by the different measurement of the incident sound power. As a result, it depends only on the aperture dimensions and position, while the type of test element has no significant influence. For the large test elements, $R_{I \mathrm{~S}}$ is systematically higher than $R_{I}$. When the partition under test is the entire wall between the rooms, the incident intensity is underestimated by ISO 10140-2 and ISO 15186-1 due to the additional incident intensity near the edges [34, 35]. In the adapted intensity method, this increased intensity near the edges is accounted for because the SPL is measured over the entire surface of the test element, including the edges and corners.

The total difference between $R$ and $R_{I \mathrm{~S}}$ is shown in Fig. 12(c) for the different test elements. $R_{I \mathrm{~S}}$ is lower than $R$ for all elements in all frequency bands. The difference is generally larger than the average difference given in ISO 15186-3 [16], which is based on measurements on windows and double plasterboard walls. This may be partly explained by the fact that the true intensity levels have been used in the simulations. The intensity level measured in front of the panel is typically lower than the true value (see section 3), 
thereby overestimating the sound reduction index. Furthermore, sound absorption by the test element or the niche boundaries, which was disregarded in the model, also leads to an underestimation of the true intensity in measurements [36].

\section{Conclusions}

A wave based model has been used to investigate the fundamental repeatability and reproducibility of sound insulation measurements according to ISO 10140-2 (R), ISO 15186-1 $\left(R_{I}\right)$ and ISO 15186-3 $\left(R_{I \mathrm{~S}}\right)$. An extensive parametric study has further shown the relative importance of measurement procedures (sensor and source positions) and geometrical parameters (room dimensions, plate dimensions, aperture dimensions and aperture placement).

The predicted repeatability of the intensity methods is better than that of the pressure

method, because it is more difficult to accurately determine the average SPL in the receiving room than the averaged sound intensity. The repeatability of $R_{I \mathrm{~S}}$ is even better because the uncertainty on the average SPL at the surface of the test elements is smaller than that on the average SPL in the source room, and the source position has less influence on the measurement results of $R_{I S}$. For intensity measurements, care should be taken that the measurement surface totally encloses the test element. Otherwise, the transmitted intensity can be underestimated by more than $3 \mathrm{~dB}$.

The overall reproducibility of $R_{I \mathrm{~S}}$ is predicted to be better for small test elements like single and double glazing, because the uncertainty caused by factors that change the incident sound field - like the source position, the dimensions of the source room and the dimensions of the aperture - is significantly larger for $R$ and $R_{I}$ than for $R_{I S}$. For large, heavy test elements, like concrete walls, the reproducibility in the lowest frequency bands is not improved by use of ISO 15186-3, because the plate modal behavior is dominating 
the sound transmission. For double plasterboard walls, the theoretical uncertainty is decreased by 1 dB by use of ISO 15186-3, because the plate modal behavior is less important for lightweight constructions. The values of $2.5 \mathrm{~dB}$ specified in the standard, however, are not reached according to the simulations.

Both the intensity methods yield systematically lower sound insulation values than the pressure method below $200 \mathrm{~Hz}$. The predicted systematic differences between the intensity methods and the pressure method are higher than the values specified in the standards.

Finally, some statements can be made concerning the uncertainty of the proposed single-number quantities, $R_{\text {living }}$ and $R_{\text {traffic }}$. If the lowest frequency bands determine the single-number quantities, which is the case for double lightweight constructions, the uncertainty of the new single-number quantities will be higher than that of the current descriptors. The simulations show that the use of the intensity method of ISO 15186-3 does not significantly improve the reproducibility for this type of structures. Furthermore, the lowest frequency bands would become even more important in the determination of the single-number quantities because $R_{I \mathrm{~S}}$ is systematically lower than $R$ at low frequencies. The reproducibility of $R_{I \mathrm{~S}}$ is better than that of $R$ and $R_{I}$ mainly for small test elements. As the extension of the frequency range, however, does not significantly increase the uncertainty of the single-number quantities for these structures $[17,20]$, the measurement uncertainty at low frequencies may be of less importance.

\section{References}

[1] D.B. Pedersen, R. Jacques, G. Raabe, and W. Maysenhölder. Measurement of the low-frequency sound insulation of building components. Acta Acust. united Ac., 86: 495-505, 2000 . 
[2] W. Wittstock. On the uncertainty of single-number quantities for rating airborne sound insulation. Acta Acust. united Ac., 93:375-386, 2007.

[3] T. Kihlman and A.C. Nilsson. The effects of some laboratory designs and mounting conditions on reduction index measurements. J. Sound Vib., 24(3):349-364, 1972.

[4] A. Cops, M. Minten, and H. Myncke. Influence of the design of transmission rooms on the sound transmission loss of glass - Intensity versus conventional method. Noise Control Eng. J., 28(3):121-129, 1987.

[5] W. Kropp, A. Pietrzyk, and T. Kihlman. On the meaning of the sound reduction index at low frequencies. Acta Acust., 2:379-392, 1994.

[6] A. Osipov, P. Mees, and G. Vermeir. Low-frequency airborne sound transmission through single partitions in buildings. Appl. Acoust., 52(3/4):273-288, 1997.

[7] ISO-140-1:1997. Acoustics - Measurement of sound insulation in buildings and of building elements - Part 1: Requirements for laboratory test facilities with suppressed flanking transmission, 1997.

[8] ISO-140-3:1995. Acoustics - Measurement of sound insulation in buildings and of building elements - Part 3: Laboratory measurements of airborne sound insulation of building elements, 1995.

[9] ISO-15186-1:2000. Acoustics - Measurement of sound insulation in buildings and of building elements using sound intensity - Part 1: Laboratory measurements, 2000.

[10] P. Fausti, R. Pompoli, and R.S. Smith. An intercomparison of laboratory measurements of airborne sound insulation of lightweight plasterboard walls. Building Acoustics, 6(2):127-140, 1999. 
[11] A. Schmitz, A. Meier, and G. Raabe. Inter-laboratory test of sound insulation measurements on heavy walls: part I - Preliminary test. Building Acoustics, 6(3-4): 159-169, 1999.

[12] A. Meier, A. Schmitz, and G. Raabe. Inter-laboratory test of sound insulation measurements on heavy walls: part II - Results of main test. Building Acoustics, 6(3-4): $171-186,1999$.

[13] ISO-10140-2:2010. Acoustics - Laboratory measurement of sound insulation of building elements - Part 2: Measurement of airborne sound insulation, 2010.

[14] ISO-10140-4:2010. Acoustics - Laboratory measurement of sound insulation of building elements - Part 4: Measurement procedures and requirements, 2010.

[15] ISO-10140-5:2010. Acoustics - Laboratory measurement of sound insulation of building elements - Part 5: Requirements for test facilities and equipment, 2010.

[16] ISO-15186-3:2002. Acoustics - Measurement of sound insulation in buildings and of building elements using sound intensity - Part 3: Laboratory measurements at low frequencies, 2002.

[17] W. Scholl, J. Lang, and V. Wittstock. Rating of sound insulation at present and in future. The revision of ISO 717. Acta Acust. united Ac., 97:686-698, 2011.

[18] V. Hongisto, J. Keränen, M. Kylliäinen, and J. Mahn. Reproducibility of the present and the proposed single-number quantities of airborne sound insulation. Acta Acust. united Ac., 98(5):811-819, 2012.

[19] J. Mahn and J. Pearse. The uncertainty of the proposed single number ratings for airborne sound insulation. Building Acoustics, 19(3):145-172, 2012. 
[20] A. Dijckmans and G. Vermeir. Numerical investigation of the repeatability and reproducibility in building acoustical measurements. In Proceedings of ISMA2012. International Conference on Noise and Vibration Engineering. Leuven, pages 33-47, 2012.

[21] ISO-140-2:1991. Acoustics - Measurement of sound insulation in buildings and of building elements - Part 2: Determination, verification and application of precision data, 1991.

[22] A. Cops and M. Minten. Comparative study between the sound intensity method and the conventional two-room method to calculate the sound transmission loss of wall constructions. Noise Control Eng. J., 22(3):104-111, 1984.

[23] R.E. Halliwell and A.C.C. Warnock. Sound transmission loss: Comparison of conventional techniques with sound intensity techniques. J. Acoust. Soc. Am., 77(6): 2094-2103, 1985.

[24] A. Cops and D. Soubrier. Sound transmission loss of glass and windows in laboratories with different room design. Appl. Acoust., 25(4):269-280, 1988.

[25] H.G. Jonasson. Sound intensity and sound reduction index. Appl. Acoust., 40:281293, 1993.

[26] R.V. Waterhouse. Interference patterns in reverberant sound fields. J. Acoust. Soc. Am., 27(2):247-258, 1955.

[27] A. Dijckmans, G. Vermeir, and W. Lauriks. Sound transmission through finite lightweight multilayered structures with thin air layers. J. Acoust. Soc. Am., 128 (6):3513-3524, 2010 . 
[28] A. Dijckmans. Wave based calculation methods for sound-structure interaction. Application to sound insulation and sound radiation of composite walls and floors. $\mathrm{PhD}$ thesis, Katholieke Universiteit Leuven, Department of Civil Engineering, 2011.

[29] A. Dijckmans and G. Vermeir. A wave based model to predict the niche effect on sound transmission loss of single and double walls. Acta Acust. united Ac., 98:111$119,2012$.

[30] W. Desmet, P. Sas, and D. Vandepitte. An indirect Trefftz method for the steadystate dynamic analysis of coupled vibro-acoustic systems. Comp. Ass. Mech. Eng. Sc., 8(2):271-288, 2001.

[31] C. Simmons. Measurement of sound pressure levels at low frequencies in rooms. Comparison of available methods and standards with respect to microphone positions. Acta Acust. united Ac., 85(1):88-100, 1999.

[32] C. Hopkins. On the efficacy of spatial sampling using manual scanning paths to determine the spatial average sound pressure level in rooms. J. Acoust. Soc. Am., 129(5):3027-3034, 2011.

[33] H.J. Martin. Sound transmission rooms - a comparison. PhD thesis, Technische Universiteit Eindhoven, 1986.

[34] W. Weise. Corrections of incident power in sound reduction index measurements. Acta Acust. united Ac., 87:475-481, 2001.

[35] F. Jacobsen and E. Tiana-Roig. Measurement of the sound power incident on the walls of a reverberation room with near field acoustic holography. Acta Acust. united Ac., 96:76-81, 2010. 
[36] B.G. van Zyl, P.J. Erasmus, and F. Anderson. On the formulation of the intensity method for determining sound reduction indices. Appl. Acoust., 22(3):213-228, 1987. 